\title{
Widespread army ant aversion among East African jumping spiders (Salticidae)
}

\author{
Ximena J. Nelson ${ }^{1}$ (i) - Samuel Aguilar-Arguello ${ }^{1} \cdot$ Robert R. Jackson $^{1,2}$
}

Received: 6 July 2019 / Accepted: 14 January 2020

(c) The Author(s) 2020, corrected publication 2020

\begin{abstract}
Jumping spiders (Salticidae) typically prey on a variety of arthropods of similar size to themselves, but rarely on ants. Using 28 salticid species from East Africa, we first investigated vision-based aversion to ants by recording latency to enter a transparent sealed chamber flanked by chambers containing living army ants (Dorylus sp.) or tsetse flies (Glossina pallidipes) of comparable size. For all species, entry latency was significantly longer when the stimuli were ants. In another experiment, we used dead ants and tsetse flies mounted in a life-like posture as stimuli; except for Goleba puella, a species with unusual retinal ultrastructure, we again found significantly longer entry latency when the stimuli were ants. Our findings imply that these salticids express an aversion specifically to ants even when restricted to using vision alone and, except for G. puella, even when relying on solely the static appearance of the insects. Having used salticids from laboratory cultures with no prior experience with ants, our findings are consistent with vision-based aversion to army ants being innate.
\end{abstract}

Keywords Object discrimination $\cdot$ Vision $\cdot$ Formicidae $\cdot$ Movement cues $\cdot$ Innate aversion $\cdot$ Myrmecomorphy

\section{Introduction}

Despite a tendency to think of insectivorous birds as the primary predators of arthropods (e.g., Gunnarsson 2007; Gunnarsson and Wiklander 2015), through sheer biomass it seems likely that the dominant predators of arthropods are actually other arthropods. For example, in temperate regions (King et al. 2013), and especially in the tropics (Davidson 1997; Davidson et al. 2003), there is evidence that the biomass of ants, which can constitute over $80 \%$ of the total biomass of arthropods, exceeds that of all vertebrates combined. Many ants also have characteristics that make them particularly dangerous for similar-sized arthropods (Sanders and Platner 2007; Mestre et al. 2012; Ramesh et al. 2016),

Electronic supplementary material The online version of this article (https://doi.org/10.1007/s10164-020-00639-1) contains supplementary material, which is available to authorized users.

Ximena J. Nelson

ximena.nelson@canterbury.ac.nz

1 School of Biological Sciences, University of Canterbury, Private Bag 4800, Christchurch 8140, New Zealand

2 International Centre of Insect Physiology and Ecology (ICIPE), Thomas Odhiambo Campus, P.O. Box 30, Mbita Point, Kenya including formidable weapons such as powerful mandibles and potent venom, along with a capacity for mobbing attacks on would-be predators and prey (Eisner 1970; Hölldobler and Wilson 1990). In response to selection pressures from particular predators, prey species may acquire predator-specific defenses. Knowing that ants can have strong impacts on the abundance of other arthropods (Halaj et al. 1997; Piñol et al. 2012) suggests that it might also be common for antvulnerable arthropods to acquire, by natural selection, acute capacity to detect, identify and then avoid ants.

Jumping spiders (family Salticidae) provide especially interesting case studies of how other arthropods adapt to ants (Huang et al. 2011; Nelson and Jackson 2011a, 2014; Jackson and Nelson 2012). Salticidae is the largest family of spiders (more than 6100 described species in 640 genera) and, like ants, a major predatory group which has diversified especially in the tropics (Maddison 2015; Prószyński 2017; Platnick 2019). However, the most distinctive characteristic of salticids is their extraordinarily good eyesight.

The salticid visual system consists of a pair of large forward-facing 'principal' eyes and three pairs of smaller eyes, collectively called the secondary eyes, situated to the side and behind the principal eyes. To discern visual detail pertaining to the shape and form of objects, an animal needs especially good spatial acuity (Land and Nilsson 2012) and 
salticids stand out by having the best spatial acuity known for terrestrial arthropods (Goté et al. 2019). To achieve this, the salticid relies primarily on its principal eyes (Land 1969; Blest et al. 1990), with the secondary eyes serving other functions, such as motion-detection (Land 1972; Zurek et al. 2010; Zurek and Nelson 2012; Jakob et al. 2018). This visual system underpins some of the most intricate vision-based predatory strategies known for animals in general (Nelson and Jackson 2011b) and enables salticids to discriminate between different kinds of prey at a distance, even in the absence of cues from other sensory modalities (Harland et al. 1999; Nelson and Jackson 2012; Cerveira et al. 2019).

That encounters with ants tend to be exceptionally dangerous for salticids is the rationale for a hypothesis that, for salticids, proficiency at identifying ants from a distance and taking evasive action is a widespread defensive strategy. Prior supporting evidence of this hypothesis has come from testing 12 salticid species from the Philippines with eight species of ants, a variety of insects (beetles, cockroaches, mosquitoes, termites, and moths) and a selection of salticids that mimic ants and that do not mimic ants (Nelson and Jackson 2006a). As the objective in those experiments was to test salticids for their capacity to identify ants on the basis of static appearance, stationary mounts made from dead arthropods in a life-like posture instead of living, active ants were used. The findings showed that the salticids were averse to being close to ants and to ant-like salticids, while showing no aversion to other insects or to non-ant-like salticids (Nelson and Jackson 2006a). The specific ant-related visual cues used by these salticids have not been investigated, and there is considerable variation between ant species, but candidates might include the ant's characteristically narrow body form, a slender pedicel where the thorax joins the abdomen, lack of wings, and thin, bare, antennae (Nelson 2010). However, instead of considering salticid ability to generalize the characteristics of ants across multiple species, here our objective was to consider only one group of ants (Dorylus sp. army ants, also known as driver ants), that are well-known to be dangerous to terrestrial arthropods (Huseynov et al. 2008; Schöning et al. 2008), and determine the effect of movement on the potential aversion that they cause to a wide variety of salticid species. Thus, here we consider whether aversion to the static appearance of army ants specifically might also be prevalent in a different salticid fauna found in East Africa, where army ants are a keystone species (Schöning et al. 2008). Here, in addition to testing with stationary mounts, we also tested salticids with live ants. This is of interest because, besides their distinctive static appearance, ants have an erratic style of locomotion, characterized by quick, fastpaced changes in direction (Shamble et al. 2017). There are a significant minority of spiders, including salticids, that specialize on eating ants and have a prey preference for ants (Jackson and Nelson 2012; Pekár and Toft 2015), and there is recent evidence that an ant-like style of moving is salient to ant-eating as well as ant-averse salticids (Nelson and Jackson 2014; Nelson and Card 2016; Shamble et al. 2017).

\section{Materials and methods}

Experiments were carried out in Mbita Point, Western Kenya, between 800 and 1400 h (laboratory photoperiod 12L:12D, lights on $700 \mathrm{~h}$ ). For test spiders, we used 28 salticid species (Table 1) from laboratory cultures (F2 or F3 generation). The cultures for Hyllus deyrollei, Parajotus cinereus, and Schenkelia modesta originated from Uganda; all others originated from Kenya. Spiders were housed individually in cages made from $250 \mathrm{ml}$ transparent plastic containers with water available through a cotton wick submerged in water which protruded into the container. Each spider was kept on a mixed diet of mosquitoes (Anopheles gambiae), from an insectary, and non-biting midges (Chaoboridae and Chironomidae), collected from the field. As Cyrba ocellata, Holcolaethis vellerea, Meleon solitaria, and Portia africana are known to prefer spiders to insects as prey, we included field-collected spiders in their diets (Argyrodes spp., Oecobius amboseli, Tetragnatha spp.). For more information about maintenance procedures, see Cerveira and Jackson (2013).

Our testing apparatus consisted of a stack of three glass chambers (Fig. 1): a 'testing chamber' in the middle with a 'top stimulus chamber' above and a 'bottom stimulus chamber' below. There was also a glass 'holding chamber', which housed the spider at the beginning of each trial and opened into the testing chamber. The 5-mm walls of all chambers were opaque, with their 2-mm tops and bottoms being transparent. For each chamber, the top was removable. During each trial, the spider could move out of the holding chamber into the testing chamber. Because the chambers were airtight, the spider could see, but not smell or touch, insects which were in the stimulus chambers. The insects used during a trial were either army ants (Dorylus sp.), which, due to their swarm-raiding foraging style, are known to be especially dangerous to salticids and other arthropods inhabiting leaf-litter (Huseynov et al. 2008; Schöning et al. 2008), or tsetse flies (Glossina pallides), which are comparatively harmless. The ants were collected as needed from the field and the flies were from laboratory culture (body length of ants 9-11 mm; body length of flies $12 \mathrm{~mm}$ ).

The holding chamber had a 'resting area' and an 'entry area' (Fig. 1). Before a trial began, the spider was taken into a glass tube (diameter $8 \mathrm{~mm}$; length $45 \mathrm{~mm}$ ) plugged with stoppers. With the spider quiescent in the tube, we removed the lid of the holding chamber and the stopper from the end of tube farthest from the spider's location within. The tube was then laid on the resting area of the holding chamber with 
Table 1 Sample sizes for aversion experiments in five conditions using 28 salticid species

\begin{tabular}{|c|c|c|c|c|c|}
\hline Species & Control & Live ants & Live flies & Dead ants & Dead flies \\
\hline Asemonea murphyae ${ }^{1}$ & 27 & 22 & 23 & 23 & 20 \\
\hline Cyrba ocellata ${ }^{2}$ & 27 & 24 & 20 & 24 & 22 \\
\hline Dendryphantes hewitti ${ }^{3}$ & 23 & 23 & 20 & 21 & 21 \\
\hline Evarcha culicivora $^{3}$ & 25 & 24 & 24 & 25 & 25 \\
\hline Evarcha ignea ${ }^{3}$ & 24 & 20 & 20 & 24 & 23 \\
\hline Goleba puella $^{1}$ & 26 & 22 & 23 & 20 & 20 \\
\hline Harmochirus bianoriformis ${ }^{3}$ & 22 & 22 & 22 & 20 & 20 \\
\hline Hasarius adansoni ${ }^{3}$ & 20 & 20 & 20 & 22 & 22 \\
\hline Heliophanus jacksoni ${ }^{3}$ & 23 & 25 & 23 & 25 & 25 \\
\hline Holcolaetis vellerea ${ }^{2}$ & 23 & 23 & 23 & 24 & 23 \\
\hline Hyllus deyrollei $i^{3}$ & 22 & 20 & 20 & 25 & 20 \\
\hline Icius mbitaensis $^{3}$ & 24 & 22 & 23 & 23 & 25 \\
\hline Meleon solitaria ${ }^{2}$ & 23 & 22 & 20 & 24 & 23 \\
\hline Menemerus congoensis ${ }^{3}$ & 25 & 20 & 23 & 25 & 24 \\
\hline Natta horizontalis ${ }^{3}$ & 20 & 20 & 20 & 20 & 20 \\
\hline Pachyballus cordiformis ${ }^{3}$ & 24 & 20 & 20 & 26 & 25 \\
\hline Parajotus cinereus ${ }^{3}$ & 22 & 22 & 22 & 22 & 23 \\
\hline Pellenes rufoclypeata ${ }^{3}$ & 22 & 20 & 20 & 23 & 22 \\
\hline Phintella aequipes ${ }^{3}$ & 24 & 22 & 22 & 25 & 22 \\
\hline Phlegra sp. ${ }^{3}$ & 22 & 20 & 20 & 20 & 20 \\
\hline Plexippus auberti ${ }^{3}$ & 24 & 24 & 23 & 26 & 23 \\
\hline Pseudicius roberti ${ }^{3}$ & 25 & 25 & 22 & 23 & 21 \\
\hline Portia africana ${ }^{2}$ & 25 & 24 & 25 & 26 & 20 \\
\hline Portia schulzi ${ }^{2}$ & 24 & 24 & 21 & 25 & 22 \\
\hline Rhene sp. ${ }^{3}$ & 25 & 24 & 23 & 23 & 20 \\
\hline Schenkelia modesta ${ }^{3}$ & 22 & 20 & 21 & 21 & 20 \\
\hline Thyene inflata ${ }^{3}$ & 29 & 26 & 24 & 25 & 24 \\
\hline Tusitala lyrata ${ }^{3}$ & 22 & 26 & 20 & 26 & 22 \\
\hline
\end{tabular}

Subfamilies: ${ }^{1}$ Asemoneinae, ${ }^{2}$ Spartaeinae, ${ }^{3}$ Salticinae (from Maddison 2015) the open end facing the entry area, and the other end against the distal end of the resting area. Next, we closed the holding chamber lid and the spider was now free to move out of the tube and into the entry area.

Trials began when the test spider went into the entry area and ended when it entered the testing chamber. The elapsed time between arriving in the entry area and entering the testing chamber was the spider's 'entry latency'. The apparatus was specifically designed to investigate the salticid's disinclination to being in the company of army ants. This is why we had a holding chamber to the side of the apparatus that forced the salticids to move into the wider 'entry area' if they wanted to venture into the vicinity of the ants (Fig. 1). We used entry latency as the metric that expressed the level to which spiders were deterred by what they saw in the stimulus chambers, with longer latencies implying stronger aversion. Once a trial began, the spider was allowed 15 min to enter the testing chamber. Whenever, a test spider began a trial and then failed to enter the testing chamber within the allowed 15-min interval, we recorded an entry latency of
900 s. Testing was dismissed on the rare occasions when spiders failed to enter the entry area within $15 \mathrm{~min}$. Sample sizes for each test are stated in Table 1.

As our objective was to detect evidence of innate aversion to army ants, no spiders were tested twice and no test spiders or their parents had prior experience with ants or tsetse flies. All spiders were of standard size (body length 4-6 $\mathrm{mm}$ ) and about half the size of the insects used in tests $(9-12 \mathrm{~mm}$ ). For the salticid species with large adult body length, we used juveniles; otherwise, we used adult males, which are usually the smaller sex. With some variation, salticids tend to prey on arthropods that are similar in size to themselves (Jackson and Pollard 1996), suggesting that, owing to the size disparity we had between test spider and stimulus insect, we minimized the likelihood that test spider would respond to the stimuli as prey.

In each trial, we had four stimulus insects of the same type in both stimulus chambers. Depending on the experiment, these were either living individuals or else mounted dead individuals. Mounts (see Jackson et al. 2005 for details) 
Fig. 1 Glass apparatus used when testing salticids for aversion to ants. a Three chambers with opaque side walls, viewed from above, stacked and staggered. Testing chamber sandwiched between two stimulus chambers (hatched shading). b Side view of apparatus when stacked for testing. Inner dimensions of all chambers: $100 \mathrm{~mm} \times 100 \mathrm{~mm}, 25 \mathrm{~mm}$ high. Chamber tops and bottoms transparent. Either ants or tsetse flies in both stimulus chambers (ants depicted here). Test spider exiting tube in resting area of holding chamber (light gray)

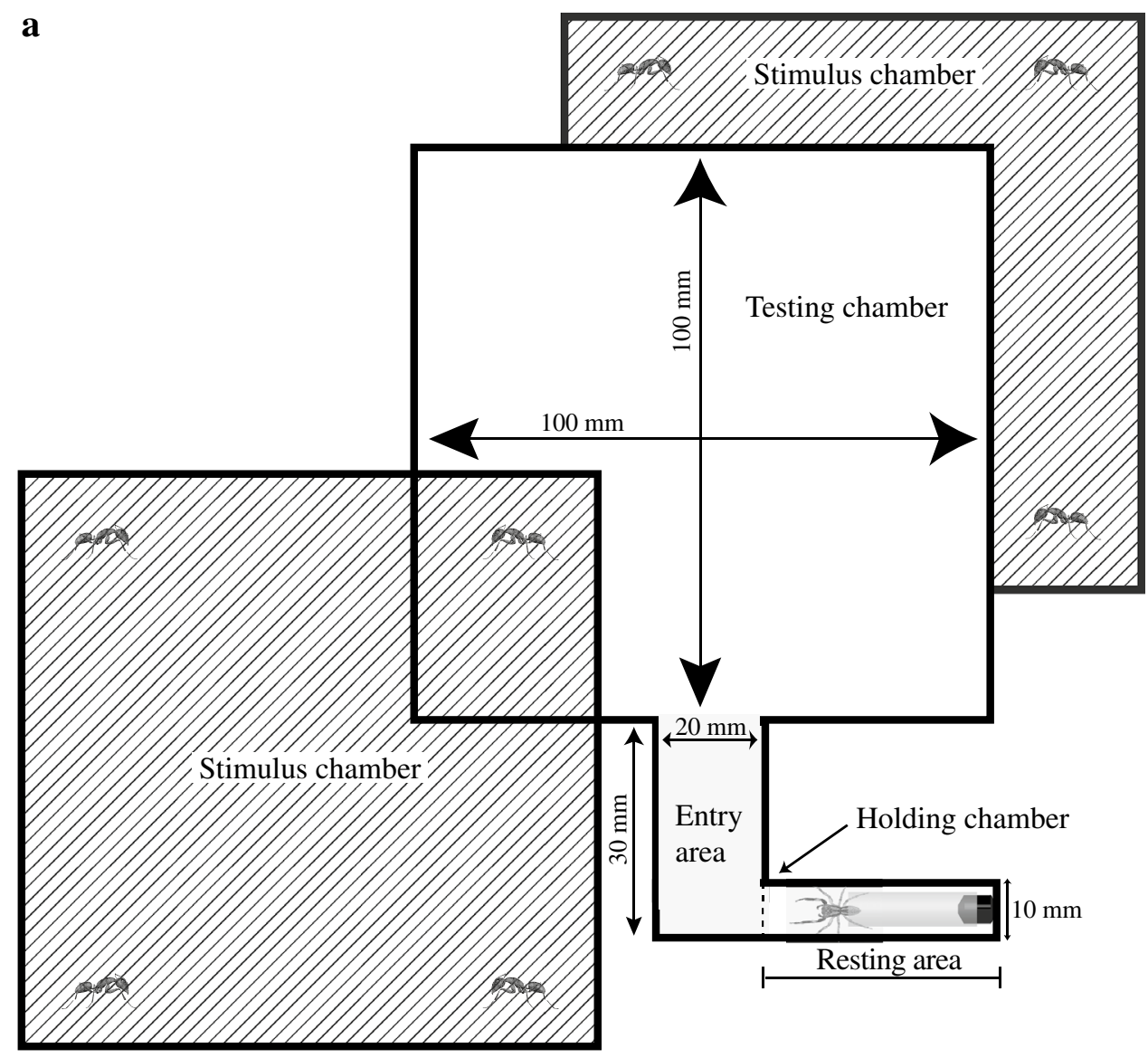

b

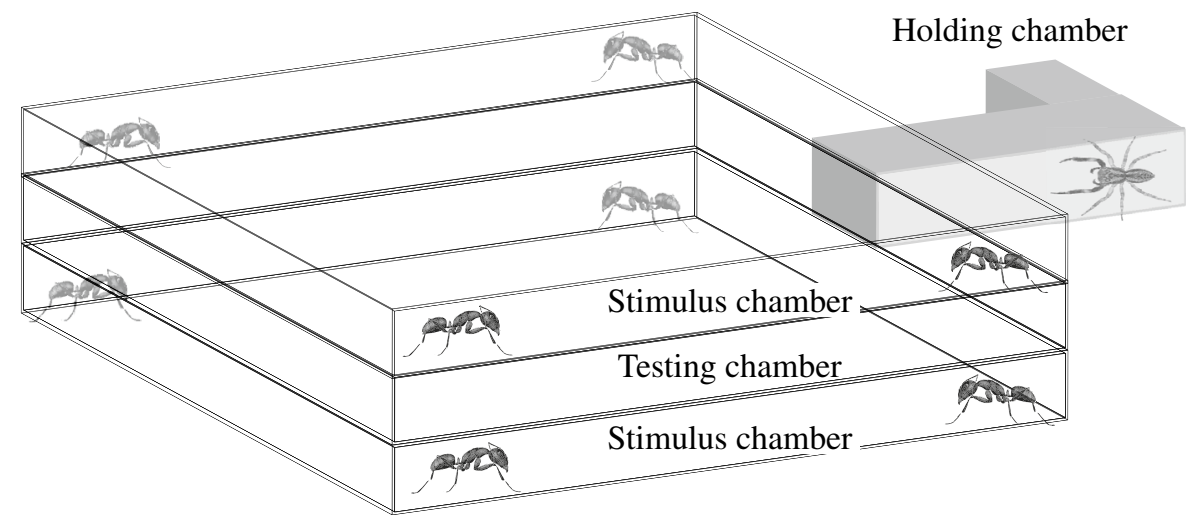

were made by immobilizing the insect under carbon dioxide, placing it in $70 \%$ ethanol for $60 \mathrm{~min}$, gluing it in place on a small cork disc, and then spraying it with an aerosol plastic adhesive (Crystal Clear Lacquer, Atsco Australia Pty). The four mounts were situated facing the center, about $15 \mathrm{~mm}$ from the edge, along two rows in each stimulus box (see Fig. 1) and were held in place with double-sided tape stuck on the underside of the cork disc. The mounts were on the bottom of the bottom stimulus chamber and on the top glass sheet of the upper stimulus chamber. There were also control trials, in which we used empty stimulus chambers, for each salticid species. If spiders can determine the morphology of an ant and correctly identify it in the absence of its characteristic movements, we would predict longer entry latencies when stationary ant mounts are visible instead of stationary tsetse flies, or empty chambers.

We used a linear mixed effects (LME) model implemented under restricted maximum likelihood (REML) in $\mathrm{R} \vee 3.3 .3$ to broadly analyze the data. As the dataset contained censored data (trials ending at $900 \mathrm{~s}$ ) and mixed 
models cannot adequately process censored data, $900 \mathrm{~s}$ latencies ( $n=535$ out of 3170 data points) were treated as missing data and were omitted from this model (known as the Complete-Case method, Wu 2010; see Supplementary Material for the LME model applied to the complete dataset). The selected model accounted for entry latency (logtransformed) as the response variable, the five treatments (control, dead flies, live flies, dead ants, and live ants) as fixed factors, and spider species as the random factor. We then applied contrast analysis (Crawley 2007) to make specific comparisons between treatments. We used the R packages 'nlme' (Pinheiro et al. 2018) and 'gmodels' (Warnes et al. 2015) for analyses and 'ggplot2' (Wickham 2009) and 'ggpubr' (Kassambara 2018) to draw the figures.

To investigate differences between species, we used twotailed Mann-Whitney $U$ tests, as the data were not normally distributed. When multiple comparisons were made using the same dataset, Bonferroni corrections were applied. In the one instance where correction caused a qualitative change, this was noted. Detailed results of this analysis can be found in Table S2.

\section{Results}

Results from the LME model showed that spiders did not differ in their latency to enter the testing chamber when exposed to dead and live ants in the stimulus chambers. Spiders also did not differ in their latency to enter the testing chamber when exposed to dead and live flies, but these latencies were significantly shorter than when spiders were flanked by ants (dead or alive). The shortest latencies were when spiders were flanked by empty, control treatment, chambers (Fig. 2, Table 2).

When species-specific differences were investigated, we found the same overall pattern as above (see detailed results in Table S2). However, in these analyses, with the exception of Thyene inflata as an outlier, there was no significant difference for any salticid species in entry latency between control tests and in tests with live flies within the stimulus boxes (Table S1; Fig. 3). Using Mann-Whitney tests, we also could not distinguish between the effect of ant movement and the static appearance of dead ants, such that test spiders were averse to ants even in the absence of movement as a variable. As found in the LME model, these analyses confirmed that entry latencies were significantly longer when flanked by mounted ants as opposed to mounted flies, with the single exception of Goleba puella (Table S1). We also found no significant differences in entry latencies when flanked by active, living ants compared with stationary ant mounts for 27 of the 28 species (Table S1). Again, G. puella was the exception, having a significantly longer entry latency

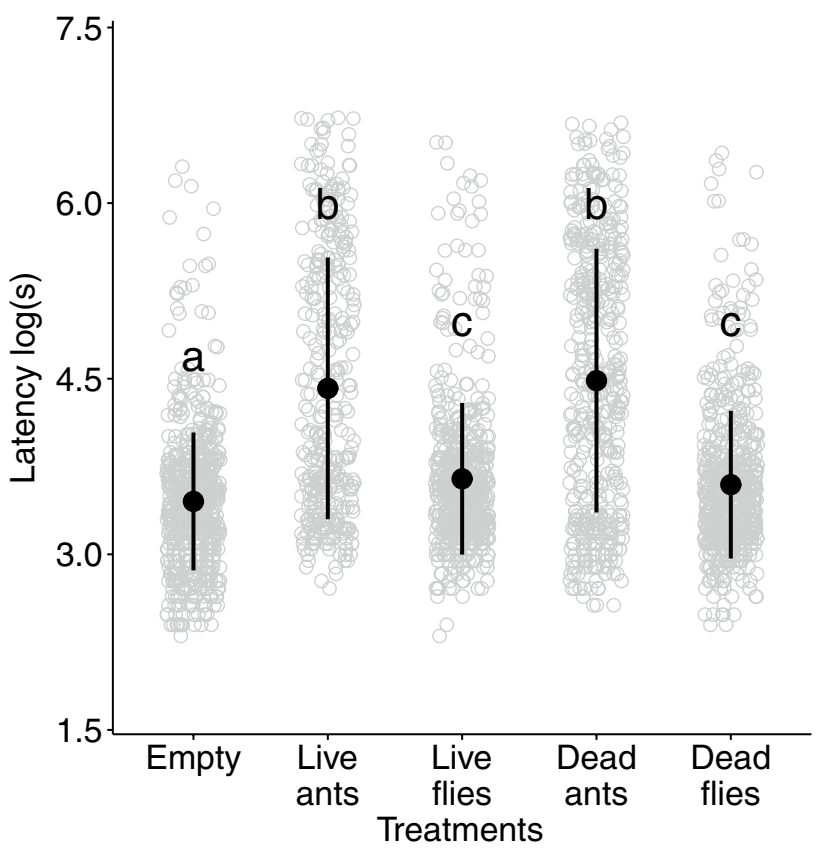

Fig. 2 Mean \pm SD of log-transformed entry latencies (s) for spiders to enter the testing chamber flanked by different stimuli. Individual data points outlined in gray. Different letters represent significant differences between treatments. Data with latencies equal to $900 \mathrm{~s}$ were omitted

when flanked by living, compared with dead, ants (Fig. 1, Table S2).

\section{Discussion}

We found evidence of a strong innate aversion to army ants among East African salticids. As in other research on salticid predatory behavior (Nelson and Jackson 2011b), we ruled out prior experience by test spiders and their parents with the prey used in our experiments here by ensuring that no test spider or its parents had prior experience with ants or tsetse flies. It is on this basis that our findings support the hypothesis that these salticids express an aversion to ants that is innate with respect to experience with ants (see O'Neil 2015). We also found evidence that this was specifically a vision-based aversion because aversion to ants was evident despite the apparatus being designed to rule out the use of chemical cues.

When stimulus chambers contained living ants instead of being empty, the entry latencies of all 28 salticids were longer when entering the testing chamber with ants. While these differences were sometimes not large, these are biologically-relevant, as salticids typically only have a few seconds in which to decide whether to attack a potential prey item. Furthermore, our results make it unlikely that we were 
Table 2 Results of the LME model omitting censored data (latency $=900 \mathrm{~s}$ )

\begin{tabular}{|c|c|c|c|c|c|}
\hline Comparison & Estimate & CI & $t$ & $d f$ & $P$ \\
\hline $\begin{array}{l}\text { Dead ants/live } \\
\text { ants }\end{array}$ & 1.065 & $0.951-1.194$ & 1.118 & 2603 & 0.263 \\
\hline $\begin{array}{l}\text { Dead ants/ } \\
\text { empty }\end{array}$ & 2.817 & $2.554-3.107$ & 21.143 & 2603 & $<0.0001$ \\
\hline $\begin{array}{l}\text { Dead ants/ } \\
\text { dead flies }\end{array}$ & 2.439 & $2.208-2.695$ & 17.909 & 2603 & $<0.0001$ \\
\hline $\begin{array}{l}\text { Dead ants/live } \\
\text { flies }\end{array}$ & 2.324 & $2.103-2.568$ & 16.894 & 2603 & $<0.0001$ \\
\hline $\begin{array}{l}\text { Live ants/ } \\
\text { empty }\end{array}$ & 2.643 & $2.376-2.941$ & 18.229 & 2603 & $<0.0001$ \\
\hline $\begin{array}{l}\text { Live ants/dead } \\
\text { flies }\end{array}$ & 2.289 & $2.054-2.551$ & 15.313 & 2603 & $<0.0001$ \\
\hline $\begin{array}{l}\text { Live ants/live } \\
\text { flies }\end{array}$ & 2.181 & $1.957-2.430$ & 14.389 & 2603 & $<0.0001$ \\
\hline $\begin{array}{l}\text { Empty/dead } \\
\text { flies }\end{array}$ & 0.865 & $0.790-0.948$ & -3.153 & 2603 & 0.001 \\
\hline $\begin{array}{l}\text { Empty/live } \\
\text { flies }\end{array}$ & 0.825 & $0.752-0.904$ & -4.204 & 2603 & $<0.0001$ \\
\hline $\begin{array}{l}\text { Dead flies/live } \\
\text { flies }\end{array}$ & 0.952 & $0.867-1.045$ & -1.039 & 2603 & 0.298 \\
\hline $\begin{array}{l}\text { Ants } \\
\text { (dead + live) } \\
\text { /flies } \\
\text { (dead + live) }\end{array}$ & 2.306 & $2.143-2.483$ & 22.701 & 1301.5 & $<0.0001$ \\
\hline
\end{tabular}

Response variable $=$ latency $(\log (\mathrm{s}))$, fixed effect $=$ treatment, random effect $=$ species. 'Species' as a random effect explains $2.11 \%$ of the overall variance of the data. Presented estimates and $95 \%$ confidence intervals $(\mathrm{CI})$ were back-transformed from the log scale

seeing a general aversion to seeing moving ant-sized objects instead of specifically ants because, when flanked by moving flies instead of ants, entry latencies were not significantly different from those in trials with dead flies. This conclusion is further supported by finding that entry latencies of spiders surrounded by live ants were significantly longer than when surrounded by live tsetse flies. However, the fact that empty stimulus chambers caused the shortest entry latencies suggests that the mere presence of some stimulus does affect their approach behavior, possibly because they take more time to visually inspect their surroundings.

It is unlikely that our findings pertained primarily to preychoice behavior instead of aversion to ants because, although all salticid species may be willing to prey on flies, the ants and flies that we used as stimuli were considerably larger than the test spiders and salticids generally prey on insects comparable to or smaller than themselves. One of the 28 salticid species that we used, Natta horizontalis, is known to express a preference for ants as prey (Jackson and van Olphen 1992), but not army ants, which are substantially larger than the small ant species typically targeted by these rather timid salticids (pers. obs.). In addition, trials with flies could be expected to have motivated the spiders to approach faster than an empty chamber, but salticids in our experiments were not responding to the tsetse flies that we used as prey: for 27 of the 28 salticid species, entry latencies in trials with tsetse flies were not significantly different from entry latencies in trials with empty stimulus boxes (Table S1). The exception was Thyene inflata. Although $T$. inflata, like the other 27 species, expressed an aversion to ants, this salticid's entry latency when tsetse flies were in the stimulus chamber was shorter than when the stimulus chamber was empty. However, T. inflata is unusual in that it often preys on tsetse flies and other similar-size insects in the field (unpublished observations).

Not all spiders are averse to ants, and, indeed, spiders that specialize at preying on ants are attracted both to their movement and static appearance (Jackson and van Olphen 1992; Pekár and Toft 2015; Nelson and Jackson 2006b; Nelson and Card 2016). However, despite their distinctive pattern of locomotion, this did not seem to be a major contributing factor to ant identification in our experiments. This corroborates previous suggestions that ant-averse salticids appear to be sufficiently deterred by the shape of the ants (Nelson and Jackson 2006a; Nelson and Card 2016) that motion, if used, is only of secondary importance-perhaps reinforcing or speeding-up identification, rather than being used as an unambiguous cue to discriminate ants. That salticids use multiple visual cues in some form of hierarchical order for the identification of arthropods is well-attested (Harland and Jackson 2000, 2002; Nelson and Jackson 2012; Dolev and Nelson 2014). While motion is an important prey-recognition cue (Bartos and Minias 2016), it appears redundant when recognizing ants as a potential threat. This finding parallels recent results in which many species of birds were found to mob cuckoo dummies with similar intensity and frequency as they mob real cuckoos, and that mobbing was more intense against cuckoos that parasitized the specific mobbing bird species (Tryjanowski et al. 2018). This suggests that selection has been exerted in birds to discriminate against this potential parasite, even in the absence of movement.

There was only one species, Goleba puella, for which we found a significant difference when we compared entry latencies from using stationary ant mounts to entry latencies from using living insects (Table S1). This species also was the only one that showed no differential response between dead ants and dead flies. Part of the explanation for G. puella being the only species for which making ant-fly discriminations seemed to require active, living individuals of these insects may pertain to the ultrastructure of the principal-eye retinas of this species having relatively poor capacity for spatial acuity (Blest et al. 1990). It is possible that comparatively poor capacity for spatial acuity may constrain $G$. puella to rely more strongly on motion-related cues. 

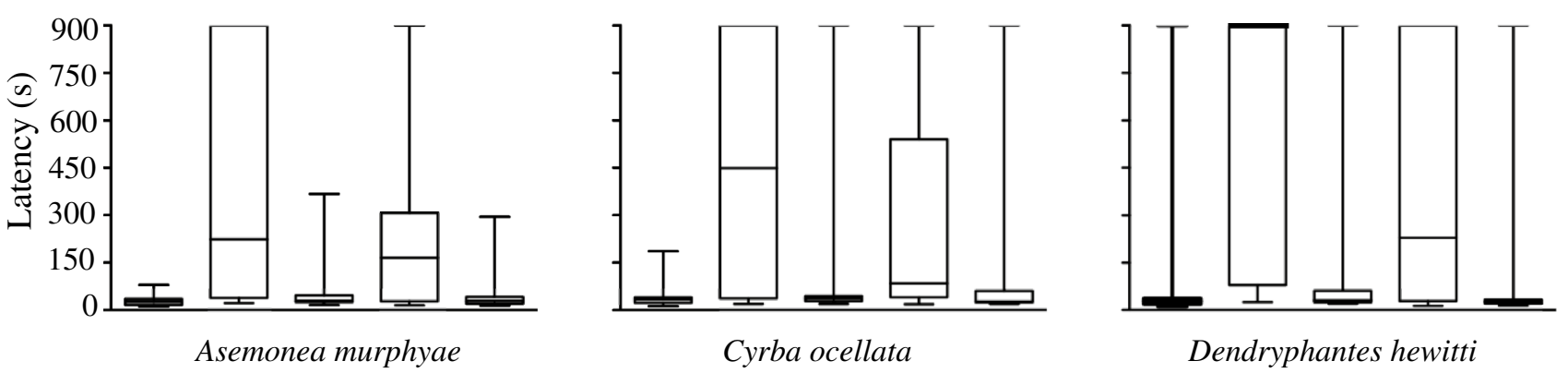

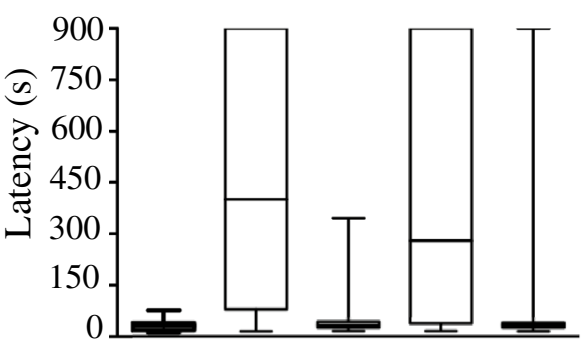

Evarcha culicivora

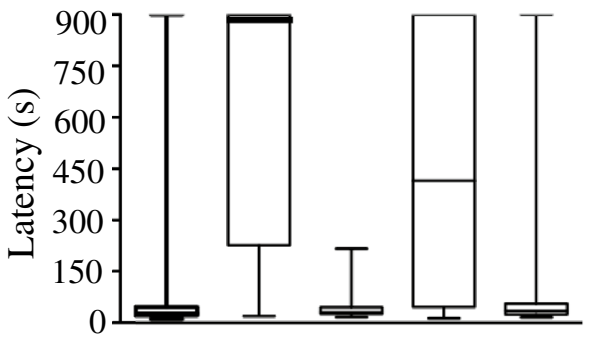

Harmorchirus bianoriformis

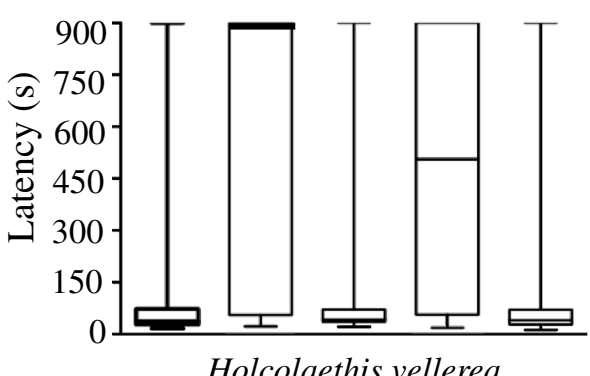

Holcolaethis vellerea

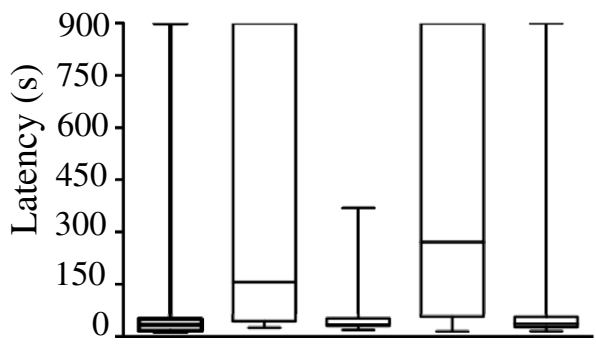

Meleon solitaria

Empty Live Live Dead Dead ants flies ants flies

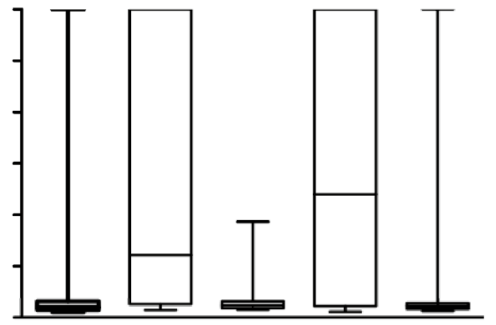

Evarcha ignea

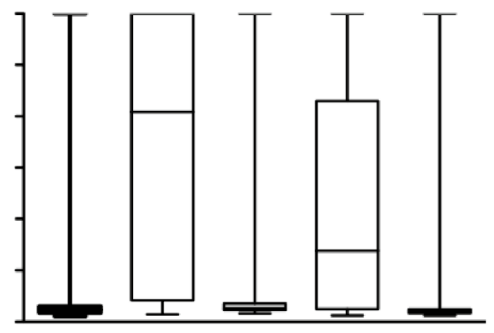

Hasarius adansoni

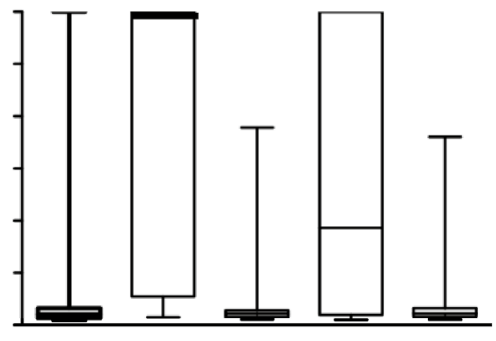

Hyllus deyrollei

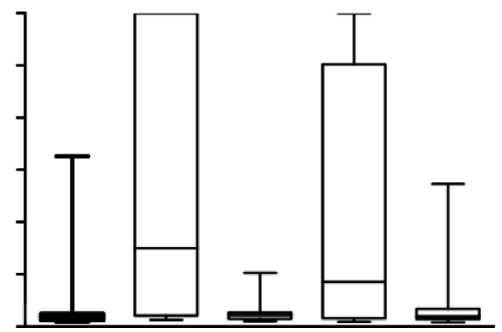

Menemerus congoensis

Empty Live Live Dead Dead ants flies ants flies

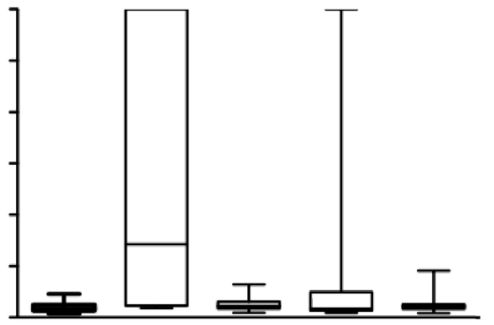

Goleba puella

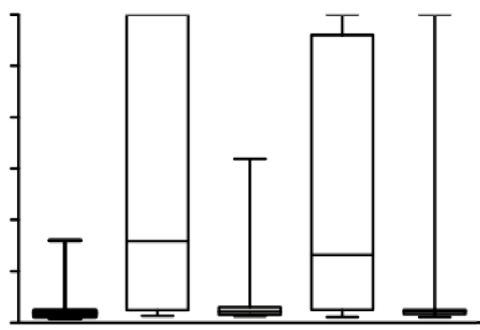

Heliophanus jacksoni
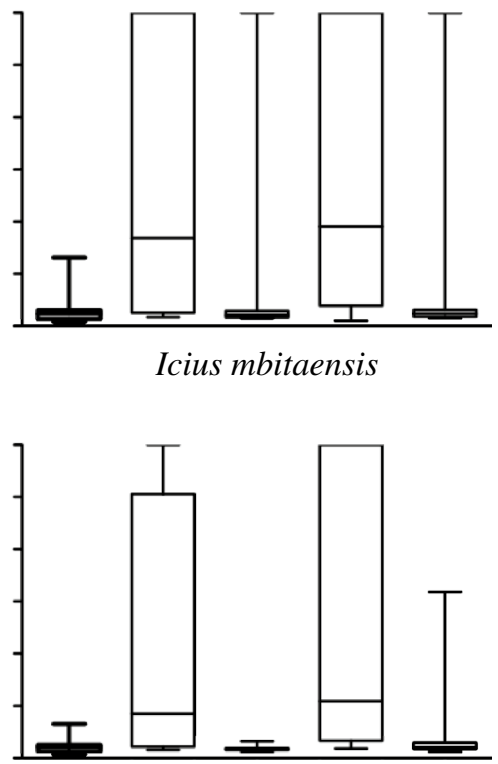

Natta horizontalis

Empty Live Live Dead Dead ants flies ants flies

Fig. 3 Boxplot (median, 1st and 3rd quartile) of entry latencies (s) for salticids to enter the testing chamber flanked by different stimuli. Whiskers depict minimum and maximum latencies. See Table 1 for sample sizes. Where medians are not visible in the boxes, these are all $900 \mathrm{~s}$ 

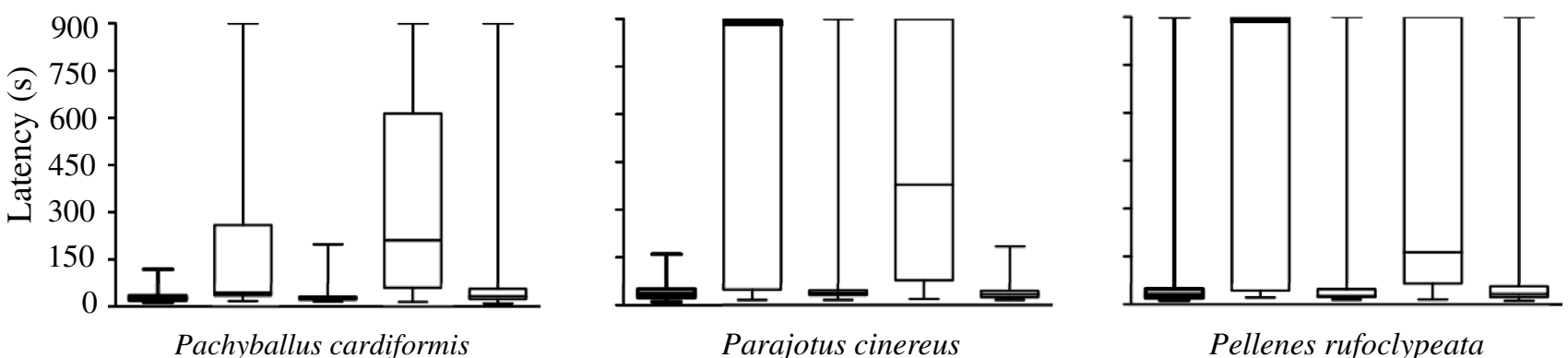

Pachyballus cardiformi
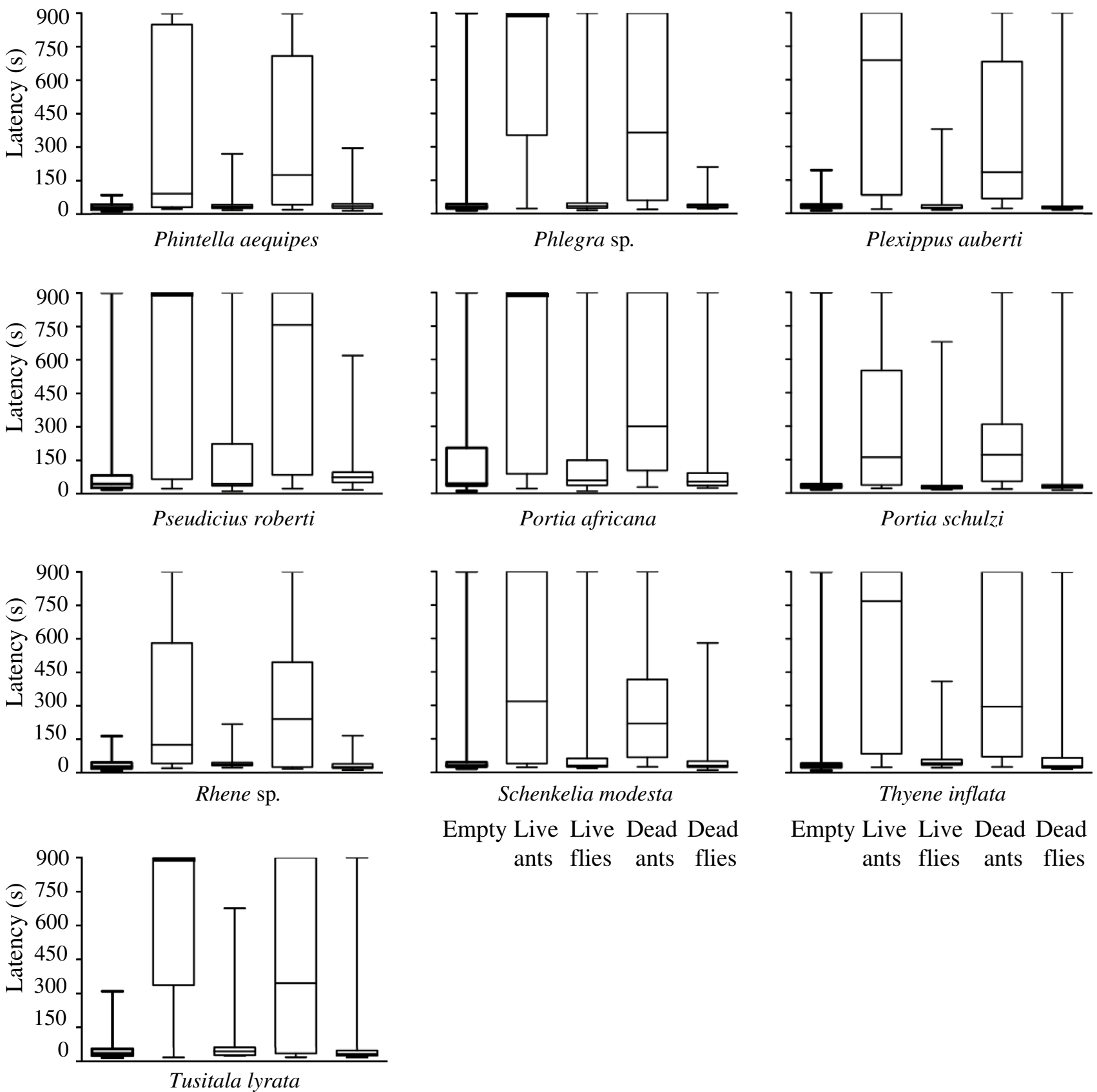

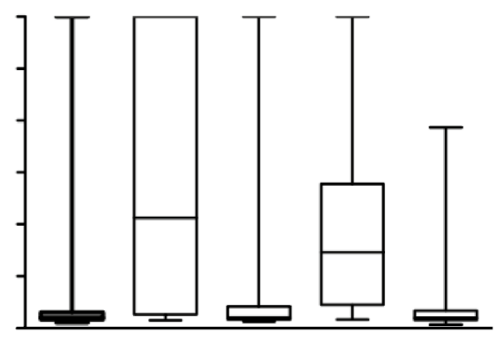

Schenkelia modesta

Empty Live Live Dead Dead ants flies ants flies

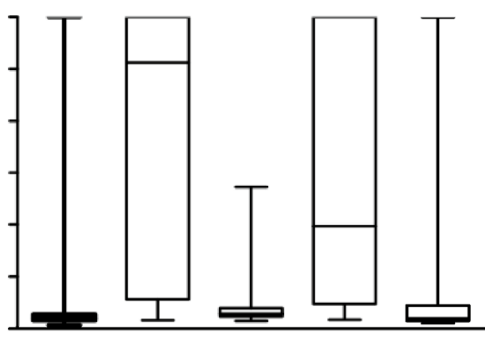

Thyene inflata

Empty Live Live Dead Dead ants flies ants flies

Empty Live Live Dead Dead ants flies ants flies

Fig. 3 (continued) 
Our findings for 28 East African salticids, along with our earlier findings for 12 salticid species from the Philippines (Nelson and Jackson 2006a) suggest that an innate capacity to visually identify and avoid ants is a geographically widespread salticid characteristic. This capacity may also be phylogenetically widespread. Seven salticid subfamilies are currently recognized (Maddison 2015), with the large majority of species belonging to the Salticinae. We now have experimental evidence of vision-based aversion to ants from three of these subfamilies: 32 salticines, six spartaeines and two asemoneines. Additionally, there is experimental evidence of innate vision-based capacity to identify ants by salticids that specialize on, and express an active preference for, ants as prey (Jackson and Nelson 2012), and by salticids that affiliate with ants for protection from their own predators (Nelson and Jackson 2014). Taken together, these studies suggest that ants have exerted especially strong selection pressures in the evolutionary shaping of salticid perceptual and decision-making processes.

Acknowledgements We thank Bonnie Humphrey and Daniel Gerhard at the University of Canterbury for statistical help, and Stephen Abok Aluoch and Godfrey Otieno Sune for their assistance at ICIPE. This research was funded by Grants from the Royal Society of New Zealand Marsden Fund (M1079, M1096, M1149) and the National Geographic Society (8676-09, 6705-00). The assistance of ICIPE, Kenya Wildlife Service and the National Museums of Kenya is gratefully acknowledged. For invaluable help with spider and ant taxonomy, we thank G.B. Edwards and Wanda Wesolowska.

Open Access This article is licensed under a Creative Commons Attribution 4.0 International License, which permits use, sharing, adaptation, distribution and reproduction in any medium or format, as long as you give appropriate credit to the original author(s) and the source, provide a link to the Creative Commons licence, and indicate if changes were made. The images or other third party material in this article are included in the article's Creative Commons licence, unless indicated otherwise in a credit line to the material. If material is not included in the article's Creative Commons licence and your intended use is not permitted by statutory regulation or exceeds the permitted use, you will need to obtain permission directly from the copyright holder. To view a copy of this licence, visit http://creativecommons.org/licenses/by/4.0/.

\section{References}

Bartos M, Minias P (2016) Visual cues used in directing predatory strikes by the jumping spider Yllenus arenarius (Araneae, Salticidae). Anim Behav 120:51-59

Blest AD, O'Carroll DC, Carter M (1990) Comparative ultrastructure of layer I receptor mosaics in the principal eyes of jumping spiders: the evolution of regular arrays of light guides. Cell Tissue Res 262:445-460

Cerveira AM, Jackson RR (2013) Love is in the air and on the ground: olfactory and tactile cues elicit visual courtship behavior by $C y r b a$ males (Araneae: Salticidae). J Arachnol 41:374-380
Cerveira AM, Jackson RR, Nelson XJ (2019) Dim-light vision in jumping spiders (Araneae, Salticidae): identification of prey and rivals. J Exp Biol In Press. https://doi.org/10.1242/jeb.198069

Crawley MJ (2007) The R book. Wiley, London

Davidson DW (1997) The role of resource imbalances in the evolutionary ecology of tropical arboreal ants. Biol J Linn Soc 61:153-181

Davidson DW, Cook SC, Snelling RR, Chua TH (2003) Explaining the abundance of ants in lowland tropical rainforest canopies. Science 300:969-972

Dolev Y, Nelson XJ (2014) Innate pattern recognition and categorization in a jumping spider. PLoS ONE 9:e97819

Eisner T (1970) Chemical defense against predation in arthropods. In: Sondheimer E, Simeone JB (eds) Chemical ecology. Academic Press, New York, pp 157-217

Goté JT, Butler PM, Zurek DB, Buschbeck EK, Morehouse NI (2019) Growing tiny eyes: how juvenile jumping spiders retain high visual performance in the face of size limitations and developmental constraints. Vis Res 160:24-36

Gunnarsson B (2007) Bird predation on spiders: ecological mechanisms and evolutionary consequences. J Arachnol 35:509-529

Gunnarsson B, Wiklander K (2015) Foraging mode of spiders affects risk of predation by birds. Biol J Linn Soc 115:58-68

Halaj J, Ross DW, Moldenke AR (1997) Negative effects of ant foraging on spiders in Douglas-fir canopies. Oecologia 109:313-322

Harland DP, Jackson RR (2000) Cues by which Portia fimbriata, an araneophagic jumping spider, distinguishes jumping-spider prey from other prey. J Exp Biol 203:3485-3494

Harland DP, Jackson RR (2002) Influence of cues from the anterior medial eyes of virtual prey on Portia fimbriata, an araneophagic jumping spider. J Exp Biol 205:1861-1868

Harland DP, Jackson RR, Macnab AM (1999) Distances at which jumping spiders (Araneae: Salticidae) distinguish between prey and conspecific rivals. J Zool 247:357-364

Hölldobler B, Wilson EO (1990) The ants. Springer-Verlag, Heidelberg

Huang JN, Cheng RC, Li D, Tso IM (2011) Salticid predation as one potential driving force of ant mimicry in jumping spiders. Proc $\mathrm{R}$ Soc Lond B 278:1356-1364

Huseynov EF, Jackson RR, Cross FR (2008) The meaning of predatory specialization as illustrated by Aelurillus m-nigrum, an ant-eating jumping spider (Araneae: Salticidae) from Azerbaijan. Behav Process 77:389-399

Jackson RR, Nelson XJ (2012) Specialized exploitation of ants (Hymenoptera: Formicidae) by spiders (Araneae). Myrmecol News 17:33-49

Jackson RR, Pollard SD (1996) Predatory behavior of jumping spiders. Annu Rev Entomol 41:287-308

Jackson RR, van Olphen A (1992) Prey-capture techniques and prey preferences of Chrysilla, Natta and Siler, ant-eating jumping spiders (Araneae, Salticidae) from Kenya and Sri Lanka. J Zool 227:163-170

Jackson RR, Nelson XJ, Sune GO (2005) A spider that feeds indirectly on vertebrate blood by choosing female mosquitoes as prey. Proc Natl Acad Sci USA 102:15155-15160

Jakob EM, Long SM, Harland DP, Jackson RR, Carey A, Searles ME, Porter AH, Canavesi C, Rolland JP (2018) Lateral eyes direct principal eyes as jumping spiders track objects. Curr Biol 28:R1075-1095

Kassambara A (2018) 'ggpubr': 'ggplot2' Based publication ready plots. R package version 0.2. https://CRAN.R-project.org/packa ge $=$ ggpubr

King JR, Warren RJ, Bradford MA (2013) Social insects dominate eastern US temperate hardwood forest macroinvertebrate communities in warmer regions. PLoS ONE 8:e75843 
Land MF (1969) Structure of retinae of the principal eyes of jumping spiders (Salticidae: Dendryphantinae) in relation to visual optics. J Exp Biol 51:443-470

Land MF (1972) Stepping movements made by jumping spiders during turns mediated by the lateral eyes. J Exp Biol 57:15-40

Land MF, Nilsson DE (2012) Animal eyes, 2nd edn. Oxford University Press, Oxford

Maddison WP (2015) A phylogenetic classification of jumping spiders (Araneae: Salticidae). J Arachnol 43:231-292

Mestre L, Piñol J, Barrientos JA, Cama A, Espadaler X (2012) Effects of ant competition and bird predation on the spider assemblage of a citrus grove. Basic Appl Ecol 13:355-362

Nelson XJ (2010) Visual cues used by ant-like jumping spiders to distinguish conspecifics from their models. J Arachnol 38:27-34

Nelson XJ, Card A (2016) Locomotor mimicry in ant-like spiders. Behav Ecol 27:700-707

Nelson XJ, Jackson RR (2006a) Vision-based innate aversion to ants and ant mimics. Behav Ecol 17:676-681

Nelson XJ, Jackson RR (2006b) Compound mimicry and trading predators by the males of sexually dimorphic Batesian mimics. Proc $\mathrm{R}$ Soc Lond B 273:367-372

Nelson XJ, Jackson RR (2011a) Flexible use of anti-predator ploys by spiders. In: Herberstein ME (ed) Spider behaviour: flexibility and versatility. Cambridge University Press, Cambridge, pp 99-126

Nelson XJ, Jackson RR (2011b) Flexibility in the foraging strategies of spiders. In: Herberstein ME (ed) Spider behaviour: flexibility and versatility. Cambridge University Press, Cambridge, pp 31-56

Nelson XJ, Jackson RR (2012) The discerning predator: decision rules underlying prey classification by a mosquito-eating jumping spider. J Exp Biol 215:2255-2261

Nelson XJ, Jackson RR (2014) Timid spider uses odor and visual cues to actively select protected nesting sites near ants. Behav Ecol Sociobiol 68:773-780

O'Neil E (2015) Relativizing innateness: innateness as the insensitivity of the appearance of a trait with respect to specified environmental variation. Biol Philos 30:211-225

Pekár S, Toft S (2015) Trophic specialisation in a predatory group: the case of prey-specialised spiders (Araneae). Biol Rev 90:744-761

Pinheiro J, Bates D, DebRoy S, Sarkar D, R Core Team (2018) nlme: linear and nonlinear mixed effects models. R package version 3.1137. https://CRAN.R-project.org/package $=$ nlme

Piñol J, Ribes E, Ribes J, Espadaler X (2012) Long-term changes and ant-exclusion effects on the true bugs (Hemiptera: Heteroptera) of an organic citrus grove. Agric Ecosyst Environ 158:127-131
Platnick NI (2019) The world spider catalog, version 20. Natural History Museum Bern. https://wsc.nmbe.ch. Accessed 7 Jun 2019. https://doi.org/10.24436/2

Prószyński J (2017) Pragmatic classification of the world's Salticidae (Araneae). Ecol Montenegrina 12:1-133

Ramesh A, Vijayan S, Sreedharan S, Somanthan H, Uma D (2016) Similar yet different: differential response of a praying mantis to ant-mimicking spiders. Biol J Linn Soc 119:158-165

Sanders D, Platner C (2007) Intraguild interactions between spiders and ants and top-down control in a grassland food web. Oecologia 150:611-624

Schöning C, Njagi W, Kinuthia W (2008) Prey spectra of two swarmraiding army ant species in East Africa. J Zool 274:85-93

Shamble PS, Hoy RR, Cohen I, Beatus T (2017) Walking like an ant: a quantitative and experimental approach to understanding locomotor mimicry in the jumping spider Myrmarachne formicaria. Proc R Soc Lond B 284:20170308

Tryjanowski P, Morelli F, Kwieciński Z, Indykiewicz Z, Møller AP (2018) Birds respond similarly to taxidermic models and live cuckoos Cuculus canorus. J Ethol 36:243-249

Warnes G, Bolker B, Lumley T, Johnson R (2015) 'gmodels': various $\mathrm{R}$ programming tools for model fitting. $\mathrm{R}$ package version 2.16.2. https://CRAN.R-project.org/package= gmodels

Wickham H (2009) 'ggplot2': elegant graphics for data analysis. Springer-Verlag, New York

Wu L (2010) Mixed effects models for complex data. Chapman \& Hall, Boca Raton

Zurek DB, Nelson XJ (2012) Saccadic tracking of targets mediated by the anterior-lateral eyes of jumping spiders. J Comp Physiol A 198:411-417

Zurek DB, Taylor AJ, Evans CS, Nelson XJ (2010) The role of the anterior lateral eyes in the vision-based behaviour of jumping spiders. J Exp Biol 213:2372-2378

Publisher's Note Springer Nature remains neutral with regard to jurisdictional claims in published maps and institutional affiliations. 